\title{
Hydrophilic and Semihydrophilic Hydration of Short-chain
} Ionic Surfactants

\author{
SUNE BACKLUND, FOLKE ERIKSSON, RAUNO FRIMAN, KENNETH RUNDT and \\ JOHAN SJÖBLOM
}

Department of Physical Chemistry, Åbo Akademi, Porthansgatan 3-5, SF-20500 Åbo 50, Finland

The molality dependence of hydration numbers of short-chain fatty acid anions (acetate to pentanoate as sodium salts), in aqueous solutions with and without sodium chloride, has been calculated from electrochemical measurements and water activity data at $298 \mathrm{~K}$. The sodium molality varied from 0.25 to $3.5 \mathrm{~mol} \mathrm{~kg} \mathrm{~kg}^{-1}$ water. In dilute solutions without sodium chloride, the hydration numbers increase with increasing chain length up to butyrate, while pentanoate has a somewhat lower hydration number. At moderate molalities, the hydration number of all anions diminishes as the molality increases. Addition of sodium chloride lowers the hydration numbers in the whole molality range studied. We distinguish between two different types of electrostatic hydration: Hydrophilic hydration of the carboxylic group and a varying semihydrophilic hydration of the methylene groups adjacent to the carboxylic group. The rest of the hydrocarbon chain is considered hydrophobic.

When discussing the molecular organization of surfactants in micelles, a primary question is how deep does water penetrate. Some authors ${ }^{1-5}$ stress that water is localized only to the head group and the counter-ion, i.e. there will be no water in the hydrocarbon part. Other models ${ }^{6-12}$ permit water beyond the head group to the adjacent methylene groups. Different experimental methods seem to give different results and the hydration might even depend on the surfactant studied. ${ }^{13}$

Our research is oriented towards sodium salts of short-chain fatty acids (sodium alkanoates). ${ }^{14}$ The shortest homologues behave approximately as ordinary electrolytes, while the longer form aggregates (micelles) to which some water is bound.9,10 One of our aims is to describe micellization ther- modynamically, ${ }^{15,16}$ which makes it necessary to consider the question of water bound to these micelles. But, firstly, the hydration of associating surfactants in dilute solutions, or unassociating short-chain homologues both in dilute and concentrated solutions, must be investigated.

Both the carboxylic group and the sodium ion bind water electrostatically, but this hydration will probably not alter much during the micelle formation and is of lesser interest here. The prime question is whether the hydrocarbon chain binds any water. In the literature ${ }^{17,18}$ one often encounters the expression "hydrophobic hydration", which does not result from strong solute-water interactions but rather from a strengthening of the water-water interactions brought about by the hydrophobic moiety. Since hydrophobically "bound" water does not enter the micelle together with the surfactant, a question of interest is whether some methylene groups are capable of binding water through an induced dipole-dipole attraction. We believe that this hydration can be detected, together with iondipole hydration, using straight-forward electrochemical methods.

\section{EXPERIMENTAL}

The experimental work involves the determination of the mean activity coefficients, $\gamma_{\mathrm{Na}, \mathrm{Cl}}$, by potentiometric measurements at different constant sodium molalities in the three-component systems: sodium alkanoate - sodium chloride - water $(\mathrm{NaB}-\mathrm{NaCl}-$ $\mathrm{H}_{2} \mathrm{O}$ ). The sodium molality varied from 0.25 to 3.5 mol kg-1 water. From these studies and earlier measured ${ }^{19}$ water activities, $a_{w}$, the mean activity coefficients, $\gamma_{\mathrm{Na}, \mathrm{B}}$, have been calculated using the 
Gibbs-Duhem equation. ${ }^{20}$ These experimental data together with literature data ${ }^{21}$ of $\gamma_{\mathrm{Na}, \mathrm{B}}^{\circ}$ and $\phi_{\mathrm{NaB}}^{\circ}$ $\left({ }^{\circ}\right.$ denotes pure sodium alkanoate solutions and $\phi$ is the osmotic coefficient) make it possible to calculate the hydration numbers of the alkanoate ions.

Chemicals. Sodium chloride and sodium acetate $(\mathrm{NaAc})$ were used as supplied by E. Merck AG (pro analysi quality). Sodium propionate, butyrate and pentanoate $(\mathrm{NaPr}, \mathrm{NaBu}$ and $\mathrm{NaVa})$ were prepared by neutralizing the corresponding fatty acid (Fluka AG purissimum quality) with sodium hydroxide (E. Merck AG "1 N Titrisol") as described earlier. ${ }^{20}$ The water was distilled and passed through an ion exchange resin immediately before use. Its conductivity was $0.5 \mu \mathrm{S} \mathrm{cm} \mathrm{cm}^{-1}$.

Potentiometric measurements. The following electrode system was used in the emf measurements

$$
\mathrm{Ag}, \mathrm{AgCl}\left|m_{\mathrm{NaB}}, m_{\mathrm{NaCl}}\right| \text { Na-glass }
$$

At constant sodium molality, $m_{\text {tot }}$, the alkanoate ion molality was varied between 0 and $m_{\text {tor }}$. The apparatus and the measuring methods have been described earlier. $^{20,22}$

\section{RESULTS}

1. Hydration numbers of the alkanoate ions in sodium alkanoate - water. Mean activity coefficients, $\gamma_{\mathrm{Na}, \mathrm{Cl}}$, in the systems sodium alkanoate-sodium chloride - water, at different sodium molalities, are given by Backlund. ${ }^{23}$ Fig. 1 shows the logarithm

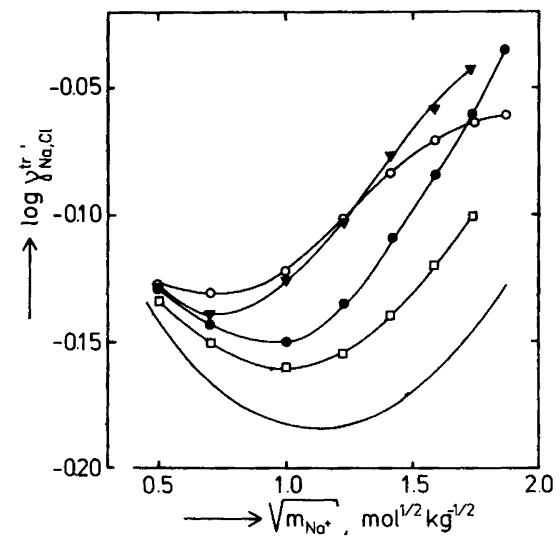

Fig. 1. The logarithm of the trace activity coefficients of sodium chloride in sodium alkanoate solutions $v$ s. square root of sodium molality at 298 K. $\square$, acetate; $\bullet$, propionate; $\nabla$, butyrate; $O$, pentanoate. The full drawn line without symbols represents the mean activity coefficient of sodium chloride in its own solution according to Ref. 21. of the trace activity coefficients of sodium chloride, together with $\log \gamma_{\mathrm{Na}, \mathrm{Cl}}^{\circ} v s$. square root of the sodium ion molality. The trace activity coefficient at constant sodium molality is defined by

$\lim _{\mathrm{NaCl}^{\rightarrow 0}} \gamma_{\mathrm{Na}, \mathrm{Cl}}=\gamma_{\mathrm{Na}, \mathrm{Cl}}^{\mathrm{tr}}$

All the curves of $\gamma_{\mathrm{Na}, \mathrm{B}}^{\circ}$ as a function of the molality have similar shapes as $\gamma_{\mathrm{Na}, \mathrm{Cl}}^{\circ}$ in aqueous solutions. ${ }^{21}$ When no association occurs $\gamma_{\mathrm{Na}, \mathrm{B}}^{\circ}$ decreases in the order of $\gamma_{\mathrm{Na}, \mathbf{V a}}^{\circ}>\gamma_{\mathrm{Na}, \mathbf{B u}}^{\circ}>\gamma_{\mathrm{Na}, \mathbf{P r}}^{\circ}>\gamma_{\mathrm{Na}, \mathbf{A c}}^{\circ}$. According to Fig. 1, $\gamma_{\mathrm{Na}, \mathrm{Cl}}^{\mathrm{tr}}$ is higher than $\gamma_{\mathrm{Na}, \mathrm{Cl}}^{\circ}$ at the corresponding sodium molality. The lower $\gamma_{\mathrm{Na}, \mathrm{B}}^{\circ}$ is, the lower is $\gamma_{\mathrm{Na}, \mathrm{Cl}}^{\mathrm{tr}}$ in that sodium alkanoate solution, i.e. $\gamma_{\mathrm{Na}, \mathrm{Cl}}^{\mathrm{tr}}$ (in $\left.\mathrm{NaVa}\right)>\gamma_{\mathrm{Na}, \mathrm{Cl}}^{\mathrm{tr}}$ (in $\mathrm{NaBu}$ ) $>\gamma_{\mathrm{Na}, \mathrm{Cl}}^{\mathrm{tr}}$ (in $\mathrm{NaPr})>\gamma_{\mathrm{Na}, \mathrm{Cl}}^{\mathrm{tr}}$ (in NaAc). A qualitative interpretation of Fig. 1 is that the hydration of the sodium alkanoates increases with increasing hydrocarbon chain length. Hydration reduces the amount of "free" water effective as solvent, thus increasing the "effective" molality of sodium chloride.

In order to give a quantitative interpretation of the results in Fig. 1, it is useful to calculate the hydration numbers of the alkanoate ions, $h_{\mathrm{B}^{-}}^{\circ}$. According to Robinson and Bates ${ }^{24}$ these can be calculated by the following formula

$h_{\mathrm{B}^{-}}^{\circ}=\frac{\ln \gamma_{\mathrm{Na}, \mathrm{B}}^{\circ}-\ln \gamma_{\mathrm{Na}, \mathrm{Cl}}^{\mathrm{tr}}}{M_{\mathrm{w}} m_{\mathrm{NaB}} \phi_{\mathrm{NaB}}^{\circ}}$

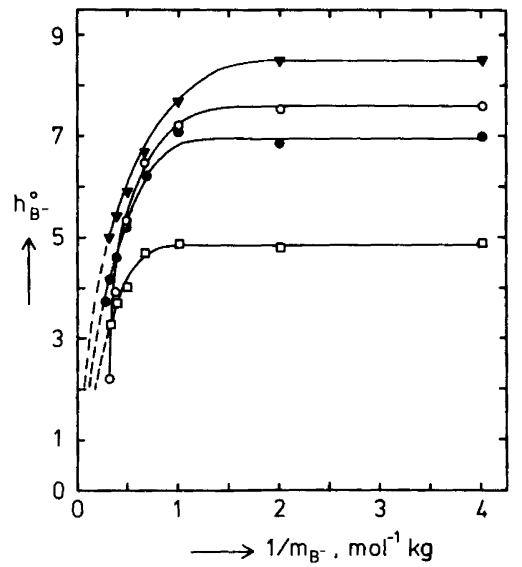

Fig. 2. Hydration numbers of alkanoate ions in sodium alkanoate-water systems vs. inverse alkanoate ion molality at $298 \mathrm{~K}$. Symbols as in Fig. 1. 
Table 1. Mean activity coefficients and water activities in sodium alkanoate-sodium chloride-water systems at $298 \mathrm{~K}$ and different constant sodium molalities, i.e. $2.0 ; 2.5 ; 3.0$ and $3.5 \mathrm{~mol} \mathrm{~kg}^{-1}$. $^{23}$ The last molality value in each $m_{\mathrm{B}}-$ column represents the constant sodium molality, $m_{\mathrm{tot}}$.

\begin{tabular}{|c|c|c|c|c|c|c|c|c|c|c|c|}
\hline $\begin{array}{l}m_{\mathrm{Ac}^{-}} \\
\mathrm{mol} \mathrm{kg}^{-1}\end{array}$ & $\gamma_{\mathrm{Na}, \mathrm{Cl}}$ & $\begin{array}{l}\mathrm{NaAc} \\
\gamma_{\mathrm{Na}, \mathbf{A c}}\end{array}$ & $a_{w}$ & $\begin{array}{l}m_{\mathrm{Pr}^{-}} \\
\mathrm{mol} \mathrm{kg}^{-1}\end{array}$ & $\gamma_{\mathrm{Na}, \mathrm{Cl}}$ & $\begin{array}{l}\mathrm{NaPr} \\
\gamma_{\mathrm{Na}, \mathrm{Pr}}\end{array}$ & $a_{\mathrm{w}}$ & $\begin{array}{l}m_{\mathrm{Bu}}- \\
\mathrm{mol} \mathrm{kg}^{-1}\end{array}$ & $\gamma_{\mathrm{Na}, \mathrm{Cl}}$ & \multicolumn{2}{|l|}{$\begin{array}{l}\mathrm{NaBu} \\
\gamma_{\mathrm{Na}, \mathrm{Bu}}\end{array}$} \\
\hline 0.3 & 0.768 & 0.877 & 0.8921 & 0.25 & 0.680 & 0.814 & 0.9304 & 0.25 & 0.684 & 0.891 & 0.9299 \\
\hline 0.6 & 0.729 & 0.888 & 0.8908 & 0.60 & 0.698 & 0.855 & 0.9283 & 0.40 & 0.694 & 0.907 & 0.9294 \\
\hline 0.9 & 0.737 & 0.899 & 0.8895 & 1.00 & 0.720 & 0.885 & 0.9260 & 0.60 & 0.709 & 0.929 & 0.9283 \\
\hline 1.2 & 0.746 & 0.910 & 0.8882 & 1.20 & 0.742 & 0.918 & 0.9238 & 0.80 & 0.724 & 0.951 & 0.9272 \\
\hline 1.5 & 0.753 & 0.925 & 0.8871 & 1.80 & 0.767 & 0.925 & 0.9215 & 1.00 & 0.740 & 0.973 & 0.9260 \\
\hline \multirow{24}{*}{3.0} & 0.794 & 0.982 & 0.8805 & 2.00 & 0.779 & 0.966 & 0.9204 & 1.20 & 0.757 & 0.995 & 0.9249 \\
\hline & & & & & & & & 1.40 & 0.776 & 1.016 & 0.9238 \\
\hline & & & & & & & & 1.60 & 0.795 & 1.038 & 0.9227 \\
\hline & & & & & & & & 1.80 & 0.816 & 1.060 & 0.9215 \\
\hline & & & & & & & & 2.00 & 0.838 & 1.082 & 0.9204 \\
\hline & & & & 0.3 & 0.726 & 0.968 & 0.8914 & 0.25 & 0.704 & 0.966 & 0.9110 \\
\hline & & & & 0.9 & 0.755 & 1.008 & 0.8876 & 0.50 & 0.720 & 0.987 & 0.9092 \\
\hline & & & & 1.5 & 0.785 & 1.050 & 0.8838 & 0.75 & 0.737 & 1.010 & 0.9073 \\
\hline & & & & 2.1 & 0.818 & 1.092 & 0.8801 & 1.00 & 0.754 & 1.033 & 0.9054 \\
\hline & & & & 2.7 & 0.853 & 1.134 & 0.8763 & 1.25 & 0.772 & 1.056 & 0.9036 \\
\hline & & & & 3.0 & 0.871 & 1.160 & 0.8745 & 1.50 & 0.792 & 1.080 & 0.9017 \\
\hline & & & & & & & & 1.75 & 0.812 & 1.103 & 0.8998 \\
\hline & & & & & & & & 2.00 & 0.832 & 1.130 & 0.8979 \\
\hline & & & & & & & & 2.25 & 0.854 & 1.155 & 0.8981 \\
\hline & & & & & & & & 2.50 & 0.876 & 1.182 & 0.8942 \\
\hline & & & & 0.35 & 0.761 & 1.042 & 0.8705 & 0.3 & 0.733 & 1.038 & 0.8910 \\
\hline & & & & 0.70 & 0.776 & 1.065 & 0.8683 & 0.6 & 0.752 & 1.067 & 0.8888 \\
\hline & & & & 1.05 & 0.793 & 1.086 & 0.8661 & 0.9 & 0.771 & 1.091 & 0.8867 \\
\hline & & & & 1.75 & 0.827 & 1.131 & 0.8618 & 1.2 & 0.790 & 1.119 & 0.8845 \\
\hline & & & & 2.45 & 0.863 & 1.178 & 0.8575 & 1.5 & 0.810 & 1.146 & 0.8825 \\
\hline & & & & 3.15 & 0.899 & 1.227 & 0.8532 & 1.8 & 0.829 & 1.168 & 0.8802 \\
\hline & & & & 3.50 & 0.926 & 1.250 & 0.8511 & 2.1 & 0.849 & 1.192 & 0.8782 \\
\hline & & & & & & & & 2.7 & 0.888 & 1.248 & 0.8740 \\
\hline & & & & & & & & 3.0 & 0.908 & 1.278 & 0.8718 \\
\hline
\end{tabular}

where $M_{\mathrm{w}}$ is the molar mass of water and the other symbols are the same as above.

The purpose of Robinson and Bates' derivation was to calculate the individual ionic activities in mixtures of two uni-uni valent unassociated electrolytes with a common hydrated cation, one hydrated anion and one unhydrated anion, i.e. $h_{\mathrm{Cl}^{-}}=0$. This non-thermodynamic assumption agrees fairly well with experimental results reported by Bockris and Reddy. ${ }^{25}$

Hydration numbers are given in Fig. 2 as a function of the inverse alkanoate ion molality.

2. Hydration numbers of the alkanoate ion in sodium alkanoate-sodium chloride-water. Water activities and mean activity coefficients, $\gamma_{\mathrm{Na}, \mathrm{Cl}}$ and $\gamma_{\mathrm{Na}, \mathrm{B}}$, are summarized by Backlund ${ }^{23}$ and in
Table 1. Hydration numbers in multicomponent systems, $h_{\mathrm{B}^{-}}$, at constant sodium molality can be calculated from ${ }^{24}$

$h_{\mathrm{B}-}=\frac{2\left(\ln \gamma_{\mathrm{Na}, \mathrm{Cl}}-\ln \gamma_{\mathrm{Na}, \mathrm{B}}\right)}{\ln a_{\mathrm{w}}}$

Hydration numbers of acetate, propionate and butyrate ions in sodium chloride solutions are presented in Fig. 3.

3. Partial molar volumes at infinite dilution in sodium alkanoate-water. The apparent molar volumes, $\phi_{v}$, of sodium alkanoates have been calculated from measured densities. ${ }^{26}$ The partial molar volumes at infinite dilution, $V_{\mathrm{NaB}}^{\infty}$ (meas.), in Table 2, were obtained by extrapolation of $\phi_{\mathrm{v}}$ to $m_{\mathrm{NaB}}^{1 / 2}=0$. 
Table 2. Calculated and measured partial molar volumes of sodium alkanoates at infinite dilution and $298 \mathrm{~K}$ compared with literature data. For futher explanation, see text.

\begin{tabular}{|c|c|c|c|c|}
\hline Sodium alkanoate & $\begin{array}{l}V_{\mathrm{NaB}}^{\infty}(\mathrm{calc} \text {. }) \\
\mathrm{cm}^{3} \mathrm{~mol}^{-1}\end{array}$ & $\begin{array}{l}V_{\mathrm{NaBB}^{3}}^{\infty} \text { (meas.) } \\
\mathrm{cm}^{3} \mathrm{~mol}^{-1}\end{array}$ & $\begin{array}{l}V_{\mathrm{NaB}_{\mathbf{B}}}^{\infty}(\text { lit. }) \\
\mathrm{cm}^{3} \mathrm{~mol}^{-1}\end{array}$ & Ref. \\
\hline $\mathrm{NaOOC}-\mathrm{H}$ & - & 24.5 & 25.1 & 42 \\
\hline $\mathrm{NaOOC}-\mathrm{CH}_{2}-\mathrm{H}$ & 39.4 & 39.3 & $39.3 ; \quad 39.2$ & $37 ; 43,44$ \\
\hline $\mathrm{NaOOC}-\left(\mathrm{CH}_{2}\right)_{2}-\mathrm{H}$ & 53.7 & 53.5 & $53.7 ; 53.8$ & $37 ; 43$ \\
\hline $\mathrm{NaOOC}-\left(\mathrm{CH}_{2}\right)_{3}-\mathrm{H}$ & 68.0 & 68.8 & $69.3 ; 69.2$ & $37 ; 43$ \\
\hline $\mathrm{NaOOC}-\left(\mathrm{CH}_{2}\right)_{3}-\mathrm{CH}_{2}-\mathrm{H}$ & 84.4 & 84.3 & $85.1 ; 85.2$ & $37 ; 43$ \\
\hline $\mathrm{NaOOC}-\left(\mathrm{CH}_{2}\right)_{3}-\left(\mathrm{CH}_{2}\right)_{2}-\mathrm{H}$ & 100.3 & 99.9 & $101.4 ; 101.1$ & $39 a ; 43$ \\
\hline $\mathrm{NaOOC}-\left(\mathrm{CH}_{2}\right)_{3}-\left(\mathrm{CH}_{2}\right)_{4}-\mathrm{H}$ & 132.1 & - & $133.0 ; 132.1$ & $39 \mathrm{a} ; 44$ \\
\hline $\mathrm{NaOOC}-\left(\mathrm{CH}_{2}\right)_{3}-\left(\mathrm{CH}_{2}\right)_{6}-\mathrm{H}$ & 163.9 & - & $164.2 ; 164.0$ & $45 ; 46$ \\
\hline $\mathrm{NaOOC}-\left(\mathrm{CH}_{2}\right)_{3}-\left(\mathrm{CH}_{2}\right)_{8}-\mathrm{H}$ & 195.7 & - & $195.5 ; 195.9$ & $45 ; 46$ \\
\hline
\end{tabular}

\section{DISCUSSION}

\section{Sodium alkanoate-water systems}

The literature report very few hydration numbers of alkanoate ions. For instance, Blatz and Waldstein $^{27}$ suggest on the basis of a Raman spectroscopic investigation that two water molecules are bound to the carboxylic group. On the other
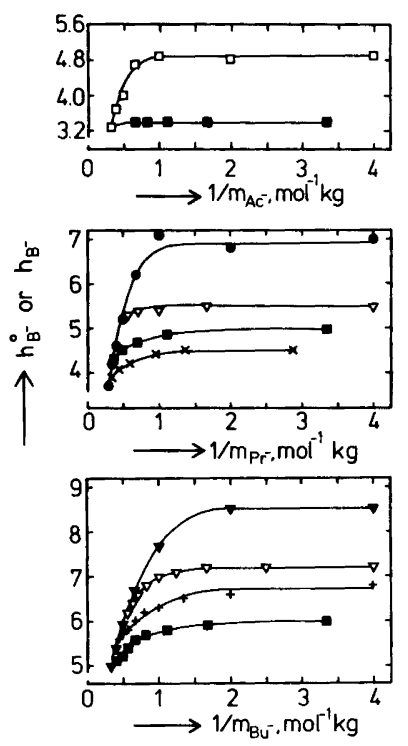

Fig. 3. Hydration numbers of alkanoate ions in sodium alkanoate-sodium chloride-water systems $v$ s. inverse alkanoate ion molality at $298 \mathrm{~K}$. $\nabla, m_{\mathrm{tot}}=2.0 ;+m_{\mathrm{tot}}=2.5 \quad \square, m_{\mathrm{tot}}=3.0 \times, m_{\mathrm{tot}}=3.5$ mol kg-1. The other symbols i.e. $\square, \bullet$ and $\nabla$ (as in Fig. 1) represent hydration numbers in sodium alkanoate - water systems. hand Glueckauf ${ }^{28}$ has calculated the hydration number 2.6 for the acetate ion.

Fig. 2 shows the molality dependence of the hydration numbers for acetate, propionate, butyrate and pentanoate ions. At high molalities $h_{\mathrm{B}^{-}}^{\circ}$ approaches zero, while a limiting value is reached at low molalities.

a. Hydration numbers at low molalities. In the absence of experimental data for sodium hexanoate (NaHex) and heptanoate (NaHept) it is possible to calculate $\gamma_{\mathrm{Na}, \mathrm{Cl}}^{\mathrm{tr}}$ from literature, ${ }^{21}$ thanks to the good validity ${ }^{23}$ of the model proposed by Lietzke and Stoughton. ${ }^{29}$ These $\gamma_{\mathrm{N}, \mathrm{Cl}}^{\mathrm{tr}}$, together with $\gamma_{\mathrm{Na}, \mathrm{B}}^{\circ}$ and $\phi_{\mathrm{NaB}}^{\circ}$, give hydration numbers for hexanoate and heptanoate ions $\left(h_{\mathrm{Hex}}^{\circ}-\approx h_{\mathrm{Hept}}^{\circ} \approx 8.5\right)$. These hydration numbers together with Fig. 2 show, that the upper limit for $h_{\mathbf{B}^{-}}^{\circ}$ regardless of the hydrocarbon chain length is about 8.5. Because formula (1) is derived for normal electrolytes, the values obtained for $h_{\mathrm{B}}^{\circ}$ must be due to the electrostatic interactions between alkanoate ions and water.

From ionization characteristics of fatty acids, Everett ${ }^{30}$ has discussed the influence of the carboxylic group on surrounding water molecules. He concluded that the water molecules around the opposite end of the hydrocarbon chain are unaffected by the ionization, if the chain is sufficiently long, i.e. for $n_{\mathrm{c}}>3\left(n_{\mathrm{c}}\right.$ is the number of carbon atoms in the hydrocarbon chain). This agrees with our results showing that $h_{\mathrm{B}}^{\circ}$-at $1 / m_{\mathrm{B}}-\geq 1 \mathrm{~mol}^{-1} \mathrm{~kg}$ increase from acetate to butyrate, while $h_{\mathrm{Va}}^{\circ}$ - is approximately one unit lower than $h_{\mathrm{Bu}}^{\circ}-$. A reasonable explanation of these effects is that the carboxylic group is capable of influencing or polarizing the nearest carbon atoms, i.e. the $\alpha$-, $\beta$ - and $\gamma$-carbon 
atoms. The coiling tendency of the hydrocarbon chain in sodium alkanoate systems has been pointed out spectroscopically ${ }^{31,32}$ and theoretically ${ }^{33}$ and this conformation could partly explain this polarization.

The influence of the carboxylic group on the water molecules has been discussed on the basis of calorimetric $^{34,35}$ and volumetric ${ }^{36-40}$ measurements. For longer alkanoate ions $\left(n_{\mathrm{c}} \geq 4\right)$, it thus seems reasonable to distinguish between three different molecular regions:

The first region is the carboxylic group, which attracts water molecules through strong coulombic forces. This kind of hydration is generally called hydrophilic hydration. ${ }^{17}$

The next region is localized to the $\alpha$-, $\beta$ - and $\gamma$ carbon atoms with an electronic structure slightly distorted by the carboxylic group, giving rise to weak electrostatic interactions between the methylene groups and water molecules. This hydration we denominate semihydrophilic hydration.

There probably does not exist any electrostatic attraction between the methylene groups beyond the $\gamma$-carbon atom and water. Therefore the concept of "hydrophobic hydration" 17,18 has been introduced to describe the effects of these methylene groups on the surrounding water.

Support to the two different hydrations and the "hydrophobic hydration" is given by partial molar volumes of the sodium alkanoates at infinite dilution in Table 2. For the methylene groups in the polarized region we used $V^{\infty}\left(\mathrm{CH}_{2}\right)_{\mathrm{p}}=14.3 \mathrm{~cm}^{3}$ $\mathrm{mol}^{-1}$ deduced from data by Sakurai ${ }^{37}$ and for the same quantity, $V^{\infty}\left(\mathrm{CH}_{2}\right)_{\mathrm{H}}$, in the hydrophobic region Musbally et al. ${ }^{41}$ give $15.9 \mathrm{~cm}^{3} \mathrm{~mol}^{-1}$. These values, together with the partial molar volume for sodium formate, $V_{\mathrm{NaFo}}^{\infty}$, given by Millero, ${ }^{42}$ are the basis of the calculated volumes, $V_{\mathrm{NaB}}^{\infty}$ (calc.), in Table 2. We observe that adding a methylene group to the $\gamma$-carbon atom will increase the partial molar volume of the terminal hydrogen atom by $0.5 \mathrm{~cm}^{3}$ $\mathrm{mol}^{-1}\left(\Delta V^{\infty}(\mathrm{H})\right.$ in Formula (4)). This is due to the transfer of this atom from the polarized to the hydrophobic region.

$$
\begin{gathered}
\text { For } n_{\mathrm{c}} \leq 3 \quad V_{\mathrm{NaB}}^{\infty}(\mathrm{calc} .)=V_{\mathrm{NaFo}}^{\infty}+n_{\mathrm{c}} V^{\infty}\left(\mathrm{CH}_{2}\right)_{\mathrm{p}} \\
\text { For } n_{\mathrm{c}}>3 \quad V_{\mathrm{NaB}}^{\infty}(\mathrm{calc} .)=V_{\mathrm{NaFo}_{0}}^{\infty}+3 V^{\infty}\left(\mathrm{CH}_{2}\right)_{\mathrm{p}}+ \\
+\left(n_{\mathrm{c}}-3\right) V^{\infty}\left(\mathrm{CH}_{2}\right)_{\mathrm{H}}+\Delta V^{\infty}(\mathrm{H})
\end{gathered}
$$

b. Hydration numbers at moderate molalities. When $1 / m_{\mathrm{B}}$ - becomes smaller than $1 \mathrm{~mol}^{-1} \mathrm{~kg}$ in
Fig. 2, we notice a decrease in the hydration numbers. This trend has earlier been reported for aqueous solutions of ions, ${ }^{4-50}$ and it is, hence, not specific to our systems. The decrease in $h_{i}$ for an ion $i$ with increasing molality, can probably be explained by an equilibrium between bound and "free" water. The observed change in $h_{\mathbf{B}}^{\circ}$ - is greater than the ordinary decrease in $h_{i}{ }^{47}$ This is probably due to a weakening in the attraction forces in the polarized region. At increased molality, the distance between the alkanoate ion and the positively charged counter-ion is reduced; this could also influence the hydration of the alkanoate ion. A decreasing gauche conformation at higher molalities, for alkanoate ions longer than butyrate, may also result in a reduced hydration of the polarized region. One way to investigate the effects of the sodium ion on the hydration is to compare the corresponding hydration numbers in presence of an excess amount of sodium chloride.

\section{Sodium alkanoate-sodium chloride-watersystems}

Fig. 3 shows that the corresponding $h_{\mathrm{B}}$-values are lowered in presence of a high amount of sodium chloride. A probable interpretation is that the excess of sodium ions reduces the hydration in the polarized region, i.e. adding sodium chloride to aqueous alkanoate solutions has almost the same effect as increasing the alkanoate molality.

It is well-known that a lengthening of the hydrocarbon chain or adding an inert salt to a surfactant solution lowers the critical micelle concentration, c.m.c. Addition of sodium chloride diminishes the extent of the polarized region, and thus increases the hydrophobicity, which favours an aggregation at lower surfactant molalities, an effect similar to the lengthening of the hydrocarbon chain.

\section{CONCLUDING REMARKS}

The high values of the hydration numbers in Fig. 2 are described by two different electrostatic attractions: A hydrophilic hydration of the carboxylic group and a varying semihydrophilic hydration of the adjacent, polarized methylene groups. This is supported by Everett's ${ }^{30}$ measurements and by our hydration numbers. In this work a limiting value of $h_{\mathrm{B}}^{\circ} \approx 8.5$ is reached regardless of the 
hydrocarbon chain length, since a non-electrostatic hydration ("hydrophobic hydration") cannot be observed by our methods. The volumes in Table 2 $\left(V_{\mathrm{Na}}^{\infty}(\mathrm{calc}\right.$.)) are calculated according to the proposed hydration model and they show good agreement with our measured volumes, as well as with literature values.

Because our study is restricted to short alkanoates, some care should perhaps be taken in using these results to draw conclusions about the penetration of water into micelles formed by longer homologues. In the present work, sodium pentanoate is the only fatty acid salt able to form micellar aggregates. ${ }^{14,51,52}$ According to Fig. $2, h_{\mathrm{V}_{\mathrm{a}}}^{\circ}$ - decreases with molality almost in the same way as $h_{\mathrm{B}^{-}}^{\circ}$ for the other alkanoate ions. The low values of $h_{\mathrm{Va}}^{\circ}$ - at high molalities show that only small amounts of water are electrostatically bound to the ion before association.

Except for hydration of the charged head groups and the counterions, the only possible site for bound water molecules in ionic micelles is the polarized region. Counter-ion measurements, i.e. determinations of the degree of counter-ion binding to the micelles, and theoretical calculations of the location of these ions, together with water activity and volume measurements, can give valuable information about water in micelles.

\section{REFERENCES}

1. Mukerjee, P. J. Colloid Sci. 19 (1964) 722.

2. Stigter, D. J. Phys. Chem. 78 (1974) 2480.

3. Wennerström, H. and Lindman, B. Phys. Rep. 52 (1979) 1.

4. Wennerström, H. and Lindman, B. J. Phys. Chem. 83 (1979) 2931.

5. Lindman, B., Wennerström, H., Gustavsson, H., Kamenka, N. and Brun, B. Pure Appl. Chem. Submitted for publication.

6. Clifford, J. Trans. Faraday Soc. 61 (1965) 1276.

7. Corkill, J. M., Goodman, J. F. and Walker, T. Trans. Faraday Soc. 63 (1967) 768.

8. Tanford, C. The Hydrophobic Effect, Wiley, New York 1973, p. 54.

9. Svens, B. and Rosenholm, B. J. Colloid Interface Sci. 44 (1973) 495.

10. Friman, R., Pettersson, K. and Stenius, P. J. Colloid Interface Sci. 53 (1975) 90.

11. Tanford, C. Science 200 (1978) 1012.

12. Menger, F. M. Acc. Chem. Res. 12 (1979) 111.

13. Vikingstad, E. J. Colloid Interface Sci. 68 (1979) 287.
14. Danielsson, I. and Stenius, P. J. Colloid Interface Sci. 37 (1971) 264.

15. Eriksson, F., Eriksson, J. C. and Stenius, P. In Mittal, K. L., Ed., Solution Chemistry of Surfactants, Plenum, New York 1979, Vol. 1, p. 297.

16. Eriksson, F., Eriksson, J. C. and Stenius, P. Proc. 3rd Int. Conf. Surface and Colloid Sci., Stockholm 1979, Abstracts, pp. 14-15.

17. Desnoyers, J. E. and Jolicoeur, C. In Bockris, J. O'M. and Conway, B. E., Eds., Modern Aspects of Electrochemistry, Butterworths, London 1969, No. 5, Chapter 1.

18. Desnoyers, J. E., Arel, M., Perron, G. and Jolicoeur, C. J. Phys. Chem. 73 (1969) 3346.

19. Danielsson, I. Proc. 3rd Scandinavian Symp. Surface Chemistry, Fredensborg 1967, Nordforsk, pp. 1-7.

20. Backlund, S., Eriksson, F. and Friman, R. Acta Chem. Scand. 27 (1973) 3234.

21. Robinson, R. A. and Stokes, R. H. Electrolyte Solutions, Butterworths, London 1959.

22. Backlund, S. Acta Chem. Scand. 25 (1971) 2070.

23. Backlund, S. An Investigation of the Electrostatic and Hydrophobic Interactions in Aqueous Solutions of Surfactants and Neutral Electrolyte, Diss., Ábo Akademi, Åbo 1979.

24. Robinson, R. A. and Bates, R. G. Anal. Chem. 45 (1973) 1684.

25. Bockris, J. O'M. and Reddy, A. K. N. Modern Electrochemistry, Plenum, New York 1970, Vol. 1, p. 119.

26. Stenius, P. Acta Chem. Scand. 27 (1973) 3435.

27. Blatz, L. A. and Waldstein, P. J. Phys. Chem. 72 (1968) 2614.

28. Glueckauf, E. Trans. Faraday Soc. 51 (1955) 1235.

29. Lietzke, M. H. and Stoughton, R. W. J. Solution Chem. 1 (1972) 299.

30. Everett, D. H. Discuss. Faraday Soc. 24 (1957) 220.

31. Rosenholm, J. B., Stenius, P. and Danielsson, I. J. Colloid Interface Sci. 57 (1976) 551.

32. Rosenholm, J. B., Larsson, K. and DinhNguyen, N. Colloid Polym. Sci. 255 (1977) 1098.

33. Pyykkö, P. A simple electrostatic model for gauche-trans equilibria of ionic alkyl surfactants in pre-micellar solutions, Department of Phys. Chem., Ábo Akademi, Report B 97 (1978) 1.

34. Rüterjans, H., Schreiner, F., Sage, U. and Ackerman, T. J. Phys. Chem. 73 (1969) 986.

35. Krishnan, C. V. and Friedman, H. L. J. Solution Chem. 2 (1973) 37.

36. King, E. J. J. Phys. Chem. 73 (1969) 1220.

37. Sakurai, M. Bull. Chem. Soc. Jpn. 46 (1973) 1596.

38. a. Høiland, H. J. Chem. Soc. Faraday Trans. 1, 70 (1974) 1180; b. Acta Chem. Scand. A 28 (1974) 699. 
39. a. Sakurai, T., Komatsu, T. and Nakagawa, T. Bull. Chem. Soc. Jpn. 48 (1975) 3491; b. J. Solution Chem. 4 (1975) 511.

40. Zana, R. J. Phys. Chem. 81 (1977) 1817.

41. Musbally, G. M., Perron, G. and Desnoyers, J. E. J. Colloid Interface Sci. 48 (1974) 494.

42. Millero, F. J. Chem. Rev. 71 (1971) 147.

43. Høiland, H. Partial Molal Volumes and Compressibilities, A Study of Homologous Series of Carboxylic Acids and Alcohols in Water, Diss., Universitetet i Bergen, Bergen 1976.

44. Leduc, P.-A. and Desnoyers, J. E. Can. J. Chem. 51 (1973) 2993.

45. Vikingstad, E., Skauge, A. and Høiland, H. J. Colloid Interface Sci. 66 (1978) 240.

46. Kale, K. M. and Zana, R. J. Colloid Interface Sci. 61 (1977) 312.

47. Bockris, J. O'M. and Saluja, P. P. S. J. Phys. Chem. 76 (1972) 2140.

48. a. Högfeldt, E. Chem. Scr. 8 (1975) 23; b. Ibid. 8 (1975) 57; c. Ibid. 8 (1975) 104.

49. Goldsack, D. E., Franchetto, R. and Franchetto, A. Can. J. Chem. 54 (1976) 2953.

50. Jacobsen, T. and Skou, E. Electrochim. Acta 22 (1977) 161.

51. Stenius, P. and Filén, L. A. Prog. Colloid Polym. Sci. 56 (1975) 21.

52. Friman, R. and Stenius, P. Acta Chem. Scand. A 32 (1978) 289.

Received January 9, 1980. 